\title{
Erratum to: Comparison of radiological spino-pelvic sagittal parameters in skiers and non-athletes
}

\author{
Carl Todd ${ }^{1,2^{*}}$, Peter Kovac ${ }^{3}$, Anna Swärd ${ }^{1}$, Cecilia Agnvall ${ }^{4}$, Leif Swärd ${ }^{1}$, Jon Karlsson $^{1}$ and Adad Baranto ${ }^{1}$
}

\section{Erratum}

After publication of the original article [1], it was brought to our attention that the measurement of the Sagittal Vertebral Axis (SVA) noted throughout the text as "cm" should have read "mm". We apologise for any confusion this may have caused.

\section{Author details \\ 'Department of Orthopaedics, University of Gothenburg and Sahlgrenska University Hospital, Gothenburg, Sweden. ${ }^{2}$ The Carl Todd Clinic, 5 Pickwick Park, Park Lane, Corsham SN13 OHN, UK. ${ }^{3}$ Department of Radiology, Institute of Clinical Sciences at Sahlgrenska Academy, University of Gothenburg and Sahlgrenska University Hospital, Gothenburg, Sweden. ${ }^{4}$ Sportsmedicine Åre and Åre Ski High School, Gothenburg, Sweden.}

Received: 16 November 2016 Accepted: 16 November 2016 Published online: 22 November 2016

\section{Reference}

1. Todd C, Kovac P, Swärd A, Agnvall C, Swärd L, Karlsson J, Baranto A.

Comparison of radiological spino-pelvic sagittal parameters in skiers and non-athletes. J Orthop Surg Res. 2015;10(162):1-7.

\footnotetext{
* Correspondence: carl.todd@me.com

'Department of Orthopaedics, University of Gothenburg and Sahlgrenska University Hospital, Gothenburg, Sweden

${ }^{2}$ The Carl Todd Clinic, 5 Pickwick Park, Park Lane, Corsham SN13 OHN, UK Full list of author information is available at the end of the article
} 